\title{
Photovoltaic Generation System Applied in isolated Communities in the Amazon
}

\author{
Rômulo Pereira Cabral ${ }^{1}$, Marcos Cesar Alves Pinheiro ${ }^{1}$, Jandecy Cabral Leite ${ }^{2}$ \\ ${ }^{1}$ Centro Universitário do Norte (UNINORTE). Av. Joaquim Nabuco, 1469, Centro. Manaus-Amazonas-Brasil. CEP: 69005-290. \\ Fone: +55 (92) 32125000 . \\ ${ }^{2}$ Instituto de Tecnologia e Educação Galileo da Amazônia - ITEGAM Praça Francisco Pereira da Silva, 149, Bola da Suframa - \\ Distrito Industrial. Manaus - Amazonas - Brasil. CEP: 69073-270. Fone: +55 (92) 3639-8952 ou +55 (92) 3584-6145. \\ *romulocabralrpc@gmail.com, *jandecy.cabral@itegam.org.br
}

\begin{abstract}
Spend a dirty and finite energy matrix, whose base is fundamental today for a clean and sustainable generation is a difficult transition. The Amazon can provide relevant services, serving as a model of clean generation from the sun and how this source can help in sustainable development of the region. The aim of the paper is to show the application of photovoltaics in remote regions of the Amazon, which for lack of adequate investments or technical infeasibility of systems integration today, are not used. The methods and techniques were taken from field applications of the Light for All project with the use of Photovoltaic Mini Mills with Minirede Distribution. The results indicate that there is viability of the technology, regardless of the location of the project, indicating the importance for economic and social development of the Amazon region.
\end{abstract}

Keywords: Photovoltaic Energy, Sustainability, Social Development.

\section{Geração Fotovoltaica Aplicada em Comunidades de Sistemas isolados na Amazônia}

\section{RESUMO}

Passar de uma matriz energética suja e finita, cuja base é fundamental hoje para uma geração limpa e sustentável, é uma difícil transição. A Amazônia pode prestar relevantes serviços, servindo de modelo de geração limpa a partir do sol e como essa fonte pode ajudar no desenvolvimento sustentável da região. O objetivo do artigo é mostrar a aplicação da energia fotovoltaica em regiões isoladas do Amazonas, que por falta de investimentos adequados ou inviabilidades técnicas de integração aos sistemas hoje, não são utilizados. Os métodos e as técnicas foram retirados de aplicações de campo do projeto Luz para Todos com a utilização de Miniusinas Fotovoltaicas com Minirede de Distribuição. Os resultados alcançados indicam que existe viabilidade da tecnologia, independente da localização do empreendimento, indicando importância para o desenvolvimento econômico e social da região amazônica.

Palavras-Chave: Energia Fotovoltaica, Sustentabilidade, Desenvolvimento Social.

\section{INTRODUÇÃO}

Ambientalmente falando o Amazonas esta na vanguarda de uma economia que comumente chamada de verde, ou seja, sustentável, e ainda tem como contribuir para garantir que as mudanças climáticas globais sejam minimizadas e garantam assim, manutenção da qualidade de vida no planeta.

Os temas discutidos na Rio+20 giraram em torno de dois eixos : Um sendo o do desenvolvimento sustentável e a erradicação da pobreza, E o segundo em governança ambiental, [1], torna explicito o que já era oficiosamente conhecido, o governo brasileiro não apoia de forma clara a mudança da matriz energética para fontes mais limpas por estar equivocado em ver somente o primeiro dos eixos mencionados da Rio+20 e segundo, o ambiental que este sim irá refletir indubitavelmente quando desenvolvido na erradicação da pobreza.

A presente pesquisa justifica-se pelas oportunidades energéticas disponíveis para a Amazônia, mais especificamente para estado do Amazonas, mostrando-se de excelente oportunidade para o campo de aproveitamento de energia solar, particularmente em áreas isoladas. 
O objetivo dessa pesquisa é a de tornar conhecida uma solução que vem de encontra, por exemplo, de resoluções como a $\mathrm{n}^{\mathbf{o}} 2$, de 22 de Maio de 2003, que estabelece diretrizes para o suprimento emergencial de energia elétrica para o atendimento dos Sistemas Isolados do Norte do Brasil, em especial na região metropolitana de Manaus - AM, e da ANEEL que em sua resolução no 482, de 17 de Abril de 2012, que estabelece as condições gerais para o acesso de microgeração e minigeração distribuída aos sistemas de distribuição de energia elétrica para contribuir principalmente com a melhora da qualidade de vida dos brasileiros.

E a pergunta que fica é a de como é superar as diferenças políticas e frear ações de exploração desmedida que estão tendo consequências mundiais?

\section{REVISÃO BIBLIOGRÁFICA}

\subsection{Produção de Energia no Brasil}

No Brasil, o processo de urbanização esta tendo consequências desastrosas e descontroladas, uma vez que a demanda de serviços, equipamentos públicos, transportes, comércio, tecnologia, tem causado série transtornos na dinâmica das cidades.

Atualmente, a capacidade do planeta de suportar os impactos ambientais associados às atividades produtivas é que passa a ser percebida como um grande entrave ao desenvolvimento sustentável [2].

Hoje, pode-se dizer que o espaço mundial é predominantemente urbano e com conhecimento adquirido e tecnologia a utilização de recursos naturais deveria estar muito mais avançada na utilização de fontes limpas de energia para exemplificar, mas em muitos casos um criminoso esquecimento apeia a mente dos tomadores de decisão cometendo erros monumentais pelo mundo afora sem justiça com o meio ambiente.

A energia é um ponto chave na sociedade moderna e com essa visão moderna a forma de geração de energia deve ser sustentável e quando fala-se em ser sustentável a primeira barreira encontrada é o víeis econômico desenvolvimentista que não tem capacidade de aceitar desenvolvimento junto com não crescimento.

Afirmado por [3] em seu texto sobre energias renováveis, onde foi indicado que mantidas as atuais tendências a população mundial deverá ter um aumento em torno de 50\%, o que por si só já levanta um grito de alerta, mas que pelo menos já é consenso pelo mundo que as fontes de energia devem gerar impactos nas mudanças climáticas irrisórios.
Em uma série denominada "Sustentabilidade", manifesta-se de várias formas que a demanda energética mundial ainda continua sendo o petróleo, mesmo com todas as inversas opiniões sobre sua utilização e a solar ocupando o singelo $9^{\circ}$ lugar participando com $11 \%$ dessa demanda e afirma categoricamente que o governo é omisso em um assunto de tamanha importância deixando de lado até os discursos realizados na Rio+20 (GOLDEMBERG, 2012). Deixando ainda bem claro que defender e preservar a natureza são um feito sem igual para a sociedade, inclusive para as metas do governo brasileiro de erradicação da pobreza.

Observando outro ponto nessa problemática está a forma de geração de energia do Sistema Nacional Brasileiro cujo modelo é centralizado e pautado na geração através de unidades geradoras seja hidroelétrica ou termoelétrica, primordialmente que com essa centralização acarretam perdas consideráveis e consequentemente custos aumentados.

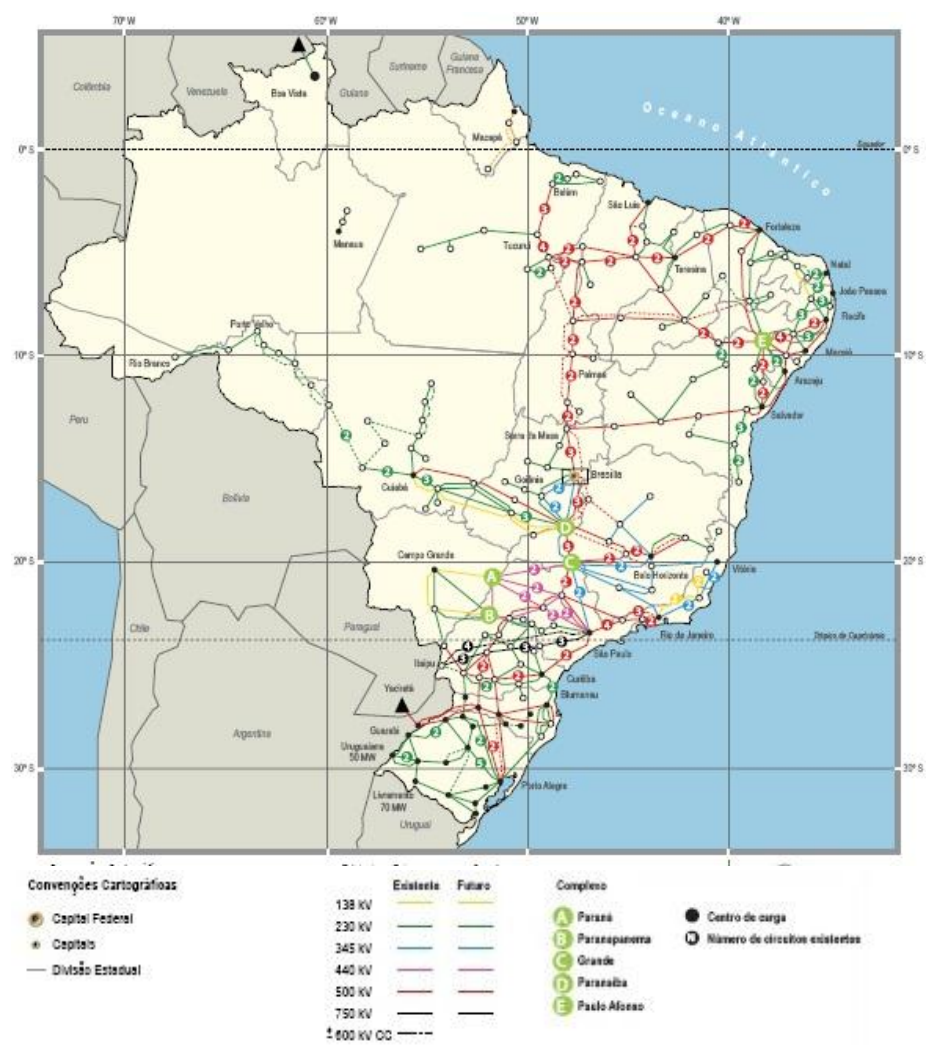

Figura 1. Sistema Nacional de Transmissão de Energia Elétrica Fonte: [4].

Acrescenta-se a quaisquer motivos para a difusão dessa ideia que a região amazônica é na sua maioria desassistida pelo sistema interligado de distribuição de eletricidade do Brasil, como visto na figura 1. 
Rômulo Cabral, Marcos Cesar, Jandecy Cabral Leite / ITEGAM-JETIA Vol.01, No 01, pp. 19-28. Março, 2015.

\subsection{Sistemas isolados}

No Brasil um grupo é responsável por todos os assuntos relacionados a sistemas isolados no norte o GTON que é composto por uma Secretaria Executiva (SGTON) e cinco Comitês Técnicos: Planejamento (CTP), Operação (CTO), Distribuição (CTD), Mercado (CTM) e Financeiro (CTF), todos coordenados pela Eletrobrás. Também conta com o apoio do Centro de Pesquisas de Energia Elétrica (Eletrobrás Cepel) em projetos pesquisa e desenvolvimento.

O marco regulatório dos sistemas isolados foi estabelecido pela Lei $\mathrm{n}^{\circ} 12.111$, de 9 de dezembro de 2009, que dispõe sobre o serviço de energia elétrica nesses sistemas, pelo Decreto ${ }^{\circ} 7246$, de 28 de julho de 2010 e pela Resolução Normativa ANEEL $n^{\circ}$ 427, de 22 de fevereiro de 2011.

As comunidades isoladas se localizam nas regiões Norte e Nordeste do país, que concentram a maior parte das comunidades brasileiras sem acesso à rede de distribuição de energia elétrica, modelo de fornecimento de eletricidade do Brasil, baseado na geração de grandes blocos de energia conectados à rede de distribuição. Esta é uma questão antiga, cujas soluções adotadas têm se mostrado, com muita frequência, insatisfatórias [5].

As dificuldades de sistemas isolados são como em qualquer sistema de produção, não havendo escala os custos aumentam, principalmente se a demanda é baixa, como no caso se apresenta onde este modelo de sistema esta localizados principalmente na região amazônica, onde a geração é baseada em usinas termelétricas que usam óleo diesel como combustível.

O modelo de geração elétrica a partir do combustível fóssil no passado recente foram as melhores soluções com o mundo numa outra política que era a desenvolvimento exploratório do meio ambiente sem medidas as consequências, com baixo custo de investimento inicial, combustíveis líquidos derivados de petróleo oriundos do monopólio do país, a Petrobras, que com esse movimento induzia a um consumo e por esse consumo a consequência de gerar impostos relativos a esse consumo, a necessidade de manutenção dos geradores também de fácil realização.

Os Sistemas Isolados do Amazonas da Figura 2 mostram características especiais como: um mercado consumidor reduzido e disperso com demanda reprimida acentuada e baixo nível de renda; alto custo de geração, baseada, essencialmente, na utilização de combustíveis derivados de petróleo, muitas vezes transportados através dos rios; receitas insuficientes para cobrir os custos operacionais das concessionárias, além de elevadas perdas técnicas nos sistemas de geração e distribuição, implicando em grandes perdas financeiras.

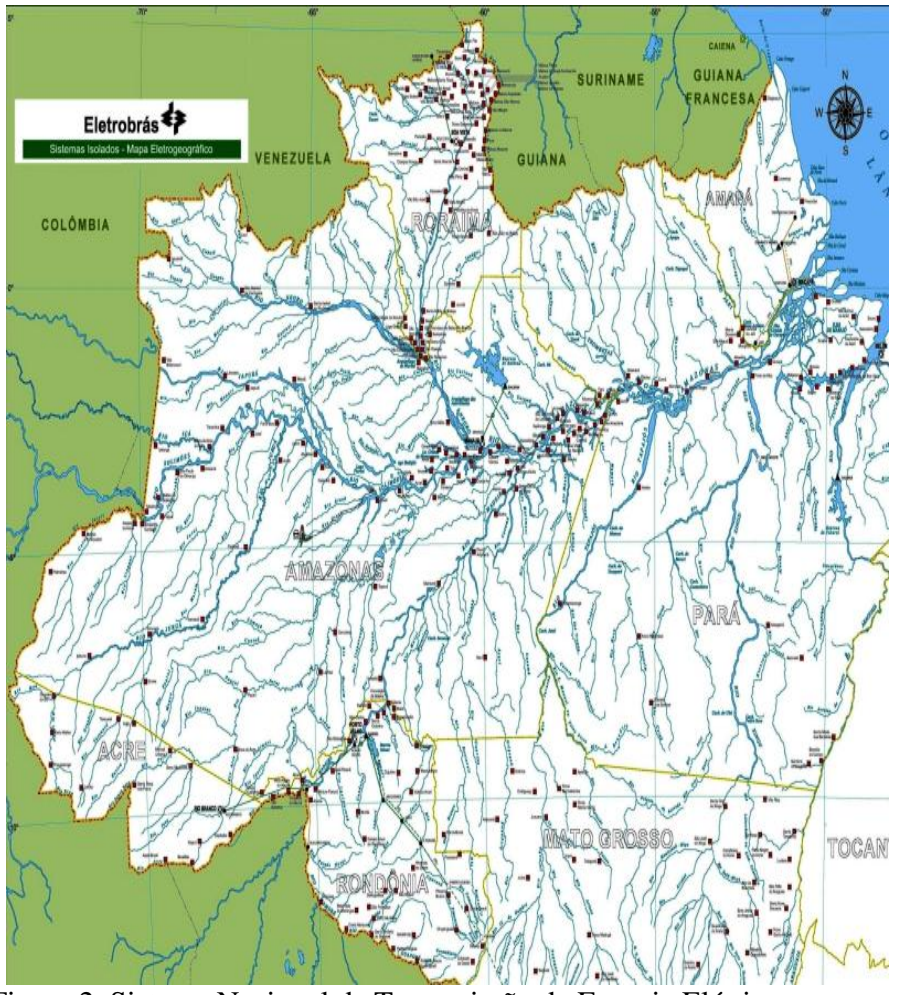

Figura 2. Sistema Nacional de Transmissão de Energia Elétrica.

Fonte: [6].

\subsection{Geração Fotovoltaica}

A fonte fotovoltaica tem uma característica que não se encontra em nenhuma outra conhecida: pode ser usada em qualquer local, gerando energia elétrica próxima ao consumidor, geralmente, sem necessidade de construção de longas linhas de transmissão [7].

A conversão da energia contida nas ondas eletromagnéticas do Sol em energia elétrica, ao incidirem fótons em uma célula, formada pela junção de dois materiais semicondutores, sendo a camada superior com semicondutores tipo $\mathrm{n}$ dopado e a camada inferior com semicondutores tipo p. Assim nos terminais da célula, é produzida uma diferença de potencial e conectando-se eletrodos e fios condutores a uma carga, ocorrerá a circulação de corrente elétrica continua [8][9].

\subsection{Aproveitamentos da energia solar no Amazonas}

Aplicabilidade do emprego da energia solar esta dívida em ativa e passiva. Para essa pesquisa o ponto de partida foi na parte ativa, como visto na Figura 3. Para o estudo do artigo a parte ativa é mais aplicável por ter em suas subclasses a Geração Centralizada, foco desde artigo, e a conexão a rede elétrica comum para abastecimento do público em geral. 


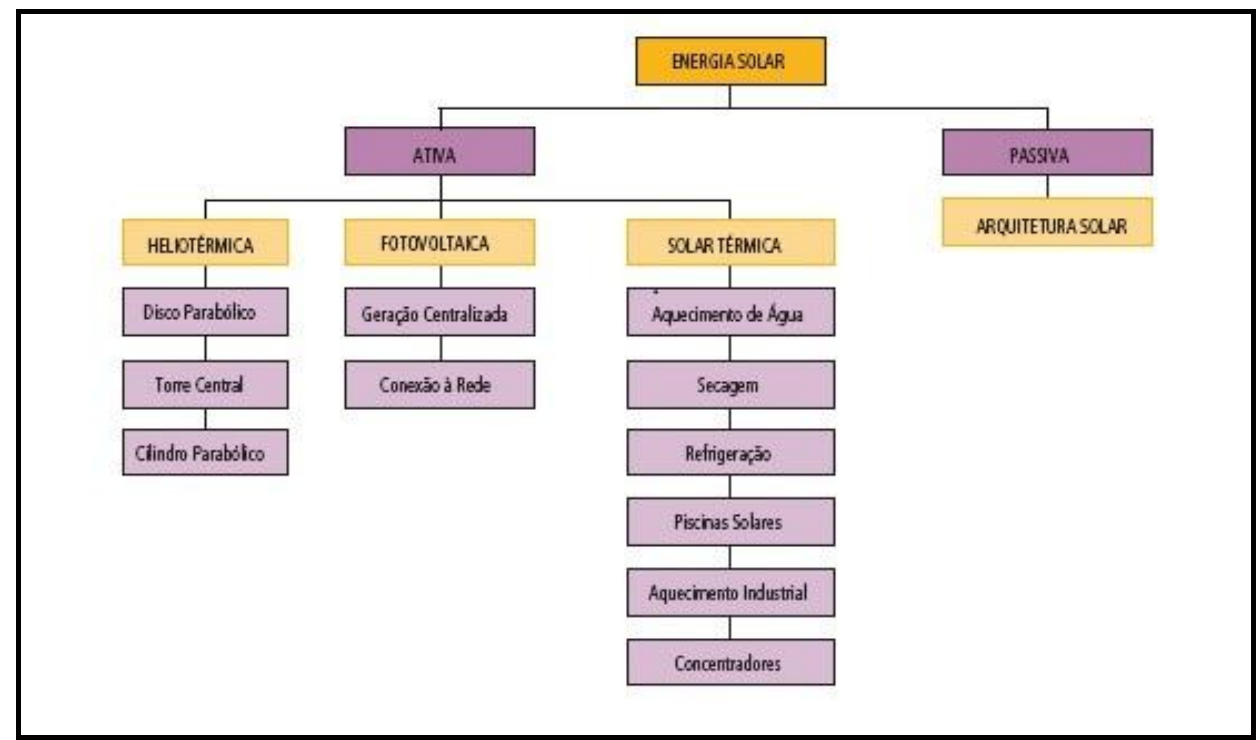

Figura 3. Fluxo das Aplicações Práticas da Energia Solar. Fonte: [10].

A tecnologia empregada para a obtenção de energia com placas solares é um processo utilizando o silício como semicondutor, e quando é atingido pelos raios solares inicia um fluxo de produção de energia, gerando corrente contínua. Um dado importante é que para a geração de energia o único fator de dependência é a intensidade de luz, quanto maior ela for maior será o fluxo de eletricidade. No modelo de sistema fotovoltaico não é necessário o brilho do sol incidindo diretamente sobre a placa, bastando para tanto ter reflexão da luz do sol, como exemplo dias nublados podem gerar mais energia que outros completamente claros.

Além das condições atmosféricas (nebulosidade, umidade relativa do ar, etc.), a disponibilidade de radiação solar, também denominada energia total incidente sobre a superfície terrestre, depende da latitude local e da posição no tempo (hora do dia e dia do ano). Isso se deve à inclinação do eixo imaginário em torno do qual a Terra promove o movimento de rotação e à trajetória elíptica que a Terra descreve ao redor do Sol, o movimento de translação [10].

Observa-se que a irradiação solar no Brasil é quase que constante mesmo com todas as variações sazonais recorrentes durante o passar dos meses do ano. Este fato é uma vantagem para do sistema fotovoltaico de energia, como mostra a figura 4.

\subsection{Recursos Solares no Brasil}

O recurso solar disponível no Brasil é considerável. Em média, anualmente, essa disponibilidade supera os $1.900 \mathrm{kWh} / \mathrm{m} 2$. Essa disponibilidade ocorre em todo o território, promovendo a fotossíntese das plantas alimentícias, das que produzem madeira e bicombustíveis, além de possibilitar a conversão térmica da energia solar para aquecimento de água. No entanto, segue sendo marginal à utilização da conversão direta da luz solar em eletricidade com a utilização de sistemas.

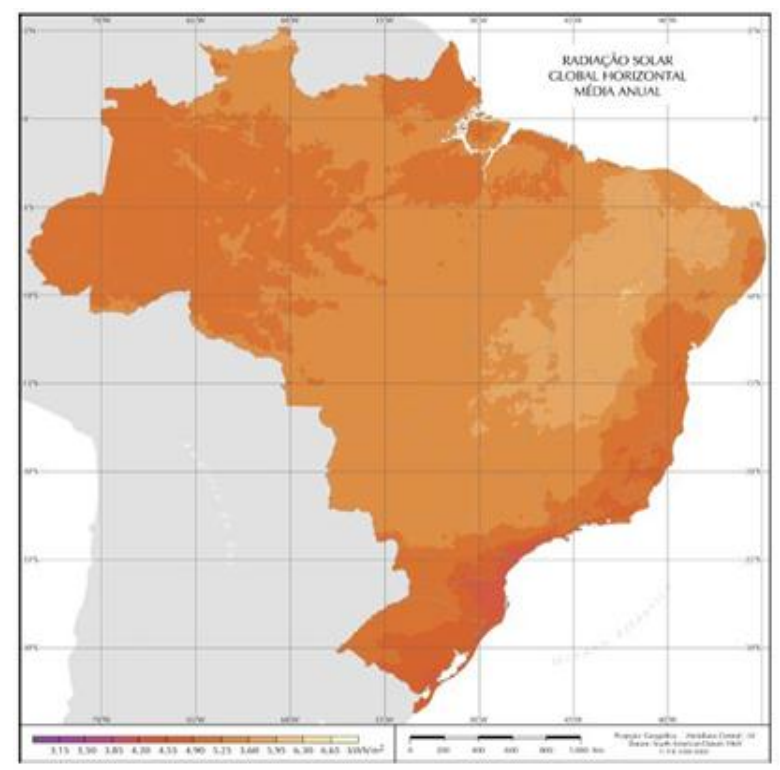

Figura 4. Mapa de Radiação Solar do Brasil.

Fonte: [9].

Atualmente, o suprimento de energia elétrica no Estado é de responsabilidade da concessionária Amazonas Energia, que possui 709.230 consumidores ativos distribuídos pelas classes residencial, industrial, comercial, rural, poder público, serviço público e outros. O fornecimento de energia elétrica no ano de 
Rômulo Cabral, Marcos Cesar, Jandecy Cabral Leite / ITEGAM-JETIA Vol.01, No 01, pp. 19-28. Março, 2015.

2010 foi de $4.808,39 \mathrm{GWh}$, sendo 3.982,82 GWh para a capital Manaus e de 825,57 GWh para o interior do Estado, demonstrando que $83 \%$ do fornecimento do estado do Amazonas está concentrado na capital e apenas $17 \%$ nos demais municípios, tendo como base a geração térmica com óleos combustíveis derivados de petróleo.

\section{MATERAIS E MÉTODOS}

O ponto principal deste trabalho é destacar a disponibilidade de energia como um fator de desenvolvimento social, econômico e de preservação ambiental. Especificamente no tocante a produção de energia, mas agora com a parceria do desenvolvimento sustentável, faz-se comparação entre as matérias primas para a geração dessa energia.

As fontes de geração de eletricidade têm características muito diferentes quanto a impactos socioambientais e econômicos de forma que se torna difícil a comparação entre elas. Mesmo havendo dados disponíveis sobre estas questões, o problema de difícil solução é como incluí-los numa análise e realizar comparações com outras fontes de eletricidade [11].

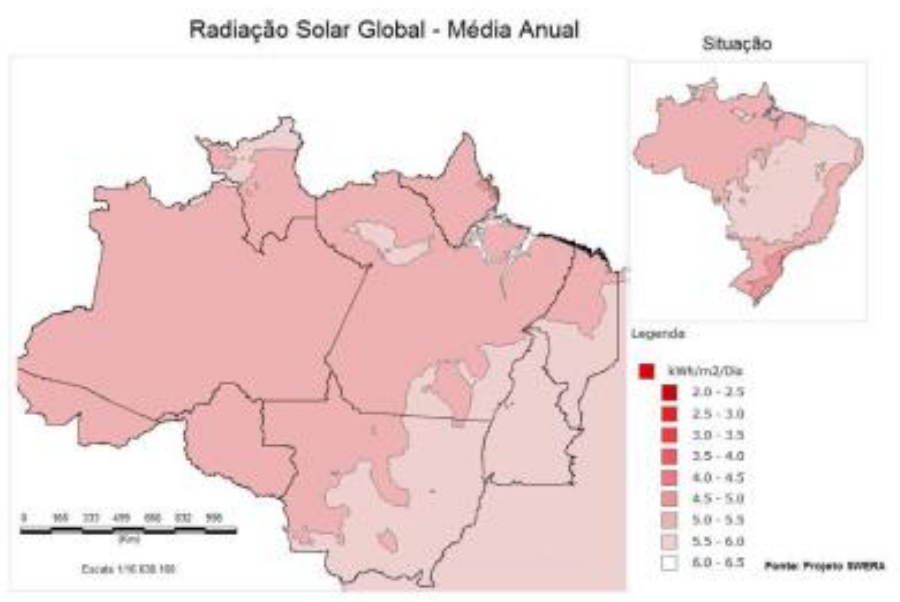

Figura 5: Radiação solar global - média anual para o território brasileiro (situação), em destaque a Amazônia.

Fonte: [4].

A energia fotovoltaica é diretamente ligada a irradiação solar, por isso para uma medição correta, foram utilizadas as cartas solarimétricas disponíveis no Atlas Brasileiro de Energia Solar em sua $1^{\circ}$ edição de 2006, e fontes como a Figura 5, mais especificamente a região norte.

\section{APLICAÇÃO DO ESTUDO DE CASO}

\subsection{A produção centralizada de energia no Amazonas}

A produção de energia no Amazonas o é como no restante do Brasil, centralizada. Uma lei a 9.704 de 7 de Julho de 1995, que entre outros assuntos concede e permite serviços públicos especiais, que é o de Produtor Independente de Energia - PIE, veio a ajudar na resolução da demanda por energia elétrica no Amazonas indicado na tabela 1, afastando para um futuro tempos de escassez de energia.

Tabela 1 - Produtores de Energia no Amazonas

\begin{tabular}{|c|c|c|c|}
\hline \multicolumn{2}{|c|}{ Local } & Geradores & MW \\
\hline \multirow{17}{*}{ 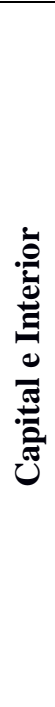 } & \multirow{8}{*}{ 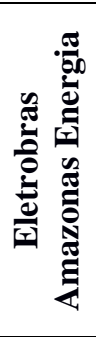 } & Geração Própria & \\
\hline & & Térmica de Aparecida & 172,0 \\
\hline & & Mauá & 436,5 \\
\hline & & UTE - Cidade Nova & 15,4 \\
\hline & & UTE - São José & 36,4 \\
\hline & & UTE - Flores & 69,0 \\
\hline & & Hidrelétrica de Balbina & 250,0 \\
\hline & & Usina Flutuante Electron & 120,0 \\
\hline & \multirow{6}{*}{ 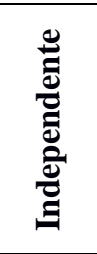 } & Geração Independente & \\
\hline & & Breitener Tambaqui & 60,0 \\
\hline & & Breitener Jaraqui & 60,0 \\
\hline & & Manaura & 60,0 \\
\hline & & Rio Amazonas & 65,0 \\
\hline & & Gera & 60,0 \\
\hline & & Sub Total & 1404,3 \\
\hline & & Interior & 383,0 \\
\hline & & Total Geral & 1787,3 \\
\hline
\end{tabular}

Fonte: [8].

Seguindo as relevantes informações sobre produção de energia temos que a região do Amazonas dispõe de 1.787,3 MW, energia que na verdade não contabiliza as perdas pela pratica de geração centralizada. Uma segunda informação e negativa vem do fato do mercado de energia na região amazônica ter uma previsão de crescimento médio de $6 \%$ a.a para os próximos 10 anos, mas sem previsão de novos investimentos que garantam o suprimento dessa demanda.

\subsection{Impactos econômicos do uso de Gás Natural X Derivados de Petróleo}

Todo o parque geracional de energia na região amazônica tem basicamente como matriz energética ou a água ou derivados de petróleo, ou seja, ou se tem hidroelétrica ou termoelétrica.

Segundo [12], fazendo um comparativo somente nas termoelétricas levando em consideração o combustível utilizado pode-se ter uma alternativa que o gás natural que somente por sua utilização já refletiria em uma redução média na ordem de 45\% no custo da produção de energia, indicados nos Figuras 6 e 7. 


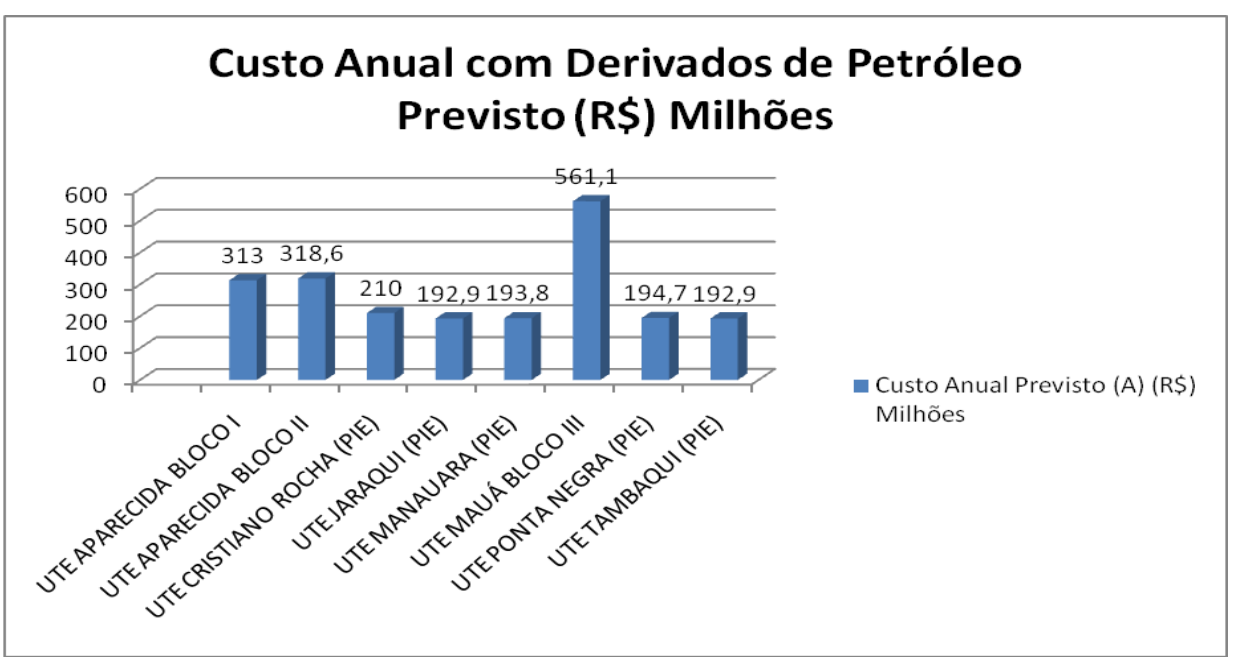

Figura 6: Custo Anual com Derivados de Petróleo Fonte: [12].

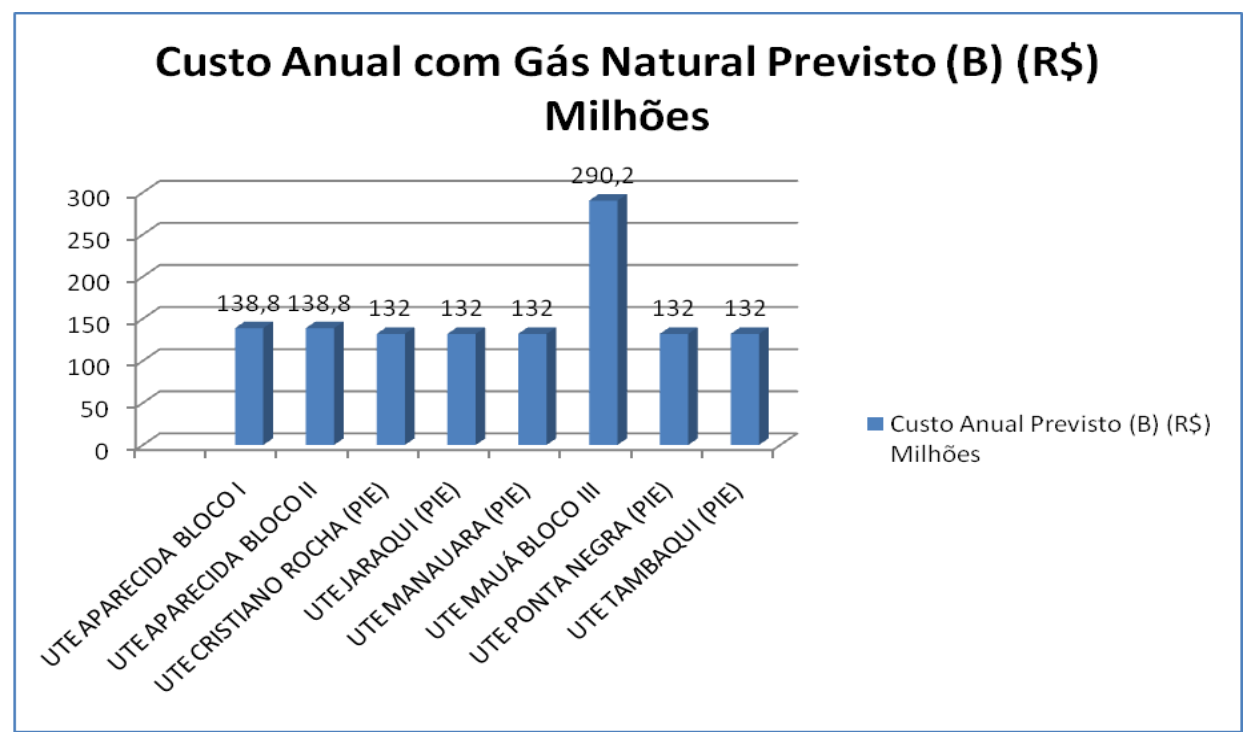

Figura 7: Custo Anual com Gás Natural Fonte: [12].

\subsection{Benefícios da geração fotovoltaica em detrimento de outras fontes}

Energia solar inicialmente foi utilizada para resolver um problema de como manter satélites de comunicação que ficam em orbita da terra funcionando, nesse quesito é uma tecnologia altamente aplicada, inclusive a de salientar que por longos períodos de tempo. Segundo Oliveira (2002), a comparação de energia elétrica produzida pela usina hidrelétrica localizada em Balbina, como exemplo no ano 1930 gerou, aproximadamente, 2,2 TWh, comparativamente através da fonte solar utilizando a mesma área seria de $380 \mathrm{TWh}$, cerca de 172 vezes maior que a energia elétrica gerada na forma que hoje existe.

A região amazônica assim como no Brasil tem uma das menores variações sazonais do mundo tornando a região ideal para essa aplicação. A economia nos combustíveis derivados de petróleo tanto como o óleo diesel como o gás seriam bastante significativas. 
Outro ponto a ser abordado é a baixa emissão de carbono por parte dessa forma de produção de energia tendo como seu único resultado poluente o calor.

No contexto local e complexo o Amazonas que seja por sua grandiosa extensão, particularidades populacionais ou excentricidades geográficas, esta numa posição difícil em termos de soluções mas invejável para aproveitar uma das mais novas linhas de produção de energia, a Solar. Em Manaus, capital do estado existindo o segundo maior parque da América Latina, o parque industrial amazonense o PIM, mantendo os ideais que levaram a criação da Zona Franca de Manaus, juntamente com lemas como o "Integrar para não Entregar", máximas dos governos brasileiros, pode-se ter uma pergunta despertando de "Seremos capazes de aproveitar essa oportunidade?".

\subsection{Análises, Resultados e Discussões}

Nos municípios citados na figura 8 as miniusinas estão instaladas nas comunidades assim divididas. No município de Autazes a cerca de $112 \mathrm{~km}$ de distância de Manaus, na comunidade de São Sebastião do Rio Preto, com 12 unidades consumidoras, em Barcelos a cerca de $400 \mathrm{~km}$ de distância de Manaus na comunidade Terra Nova, com 23 unidades consumidoras, em Beruri a cerca de $173 \mathrm{~km}$ de distância de Manaus na comunidade Nossa Senhora do Carmo, com 12 unidades consumidoras, em Eirunepé a cerca de $1160 \mathrm{~km}$ de distância de Manaus o projeto está localizada em duas localidades uma é na comunidade de Mourão com 21 unidades consumidoras e na comunidade de Santo Antônio com 15 unidades consumidoras, em Maués a cerca de $258 \mathrm{~km}$ de distância de Manaus o projeto está localizada em quatro localidades assim divididas na comunidade de Nossa Senhora de Nazaré com 16 unidades consumidoras, na comunidade de Santa Luzia com 23 unidades consumidoras e na comunidade de Santa Maria com 21 unidades consumidoras e na comunidade São José com 13 unidades consumidoras, em Novo Airão a cerca de $229 \mathrm{~km}$ de distância de Manaus com três comunidades, sendo a primeira em Aracari com 14 unidades consumidoras, em Bom Jesus do Puduari com, 27 unidades e em Sobrado com 15 unidades consumidoras.

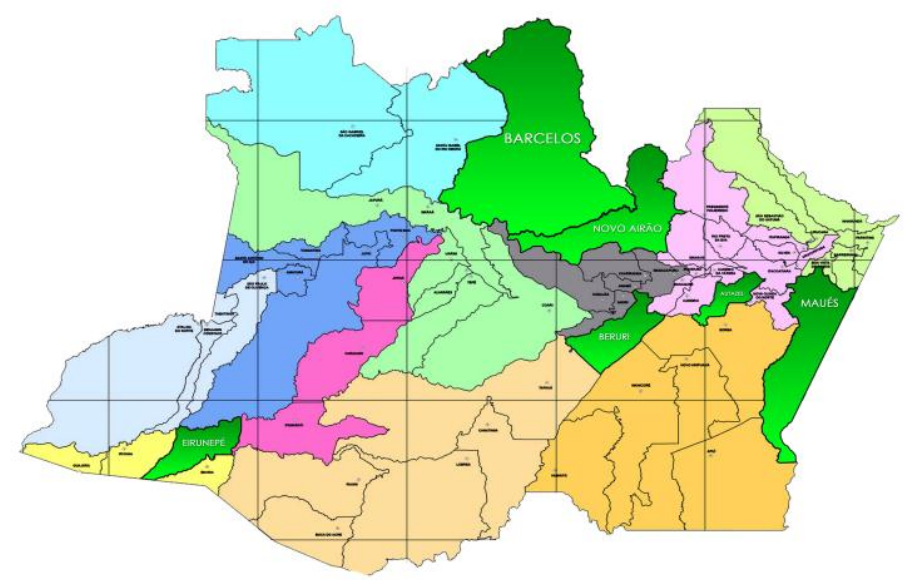

Figura 8. Distribuição geográfica dos Municípios do Programa Fonte: [8].

As unidades consumidoras distribuídas pelos 6 municípios tem variações nas quantidades de unidades consumidoras atendidas assim também a energia disponível, que onde ficam em torno de $570 \mathrm{KW} / \mathrm{h}$ para Novo Airão, $718 \mathrm{KW} / \mathrm{h}$ para Maués, Eirunepé com $311 \mathrm{KW} / \mathrm{h}$, Beruri com $126 \mathrm{KW} / \mathrm{h}$ Barcelos com $221 \mathrm{KW} / \mathrm{h}$ e Autazes com $147 \mathrm{KW} / \mathrm{h}$ como mostra o Figura 9.

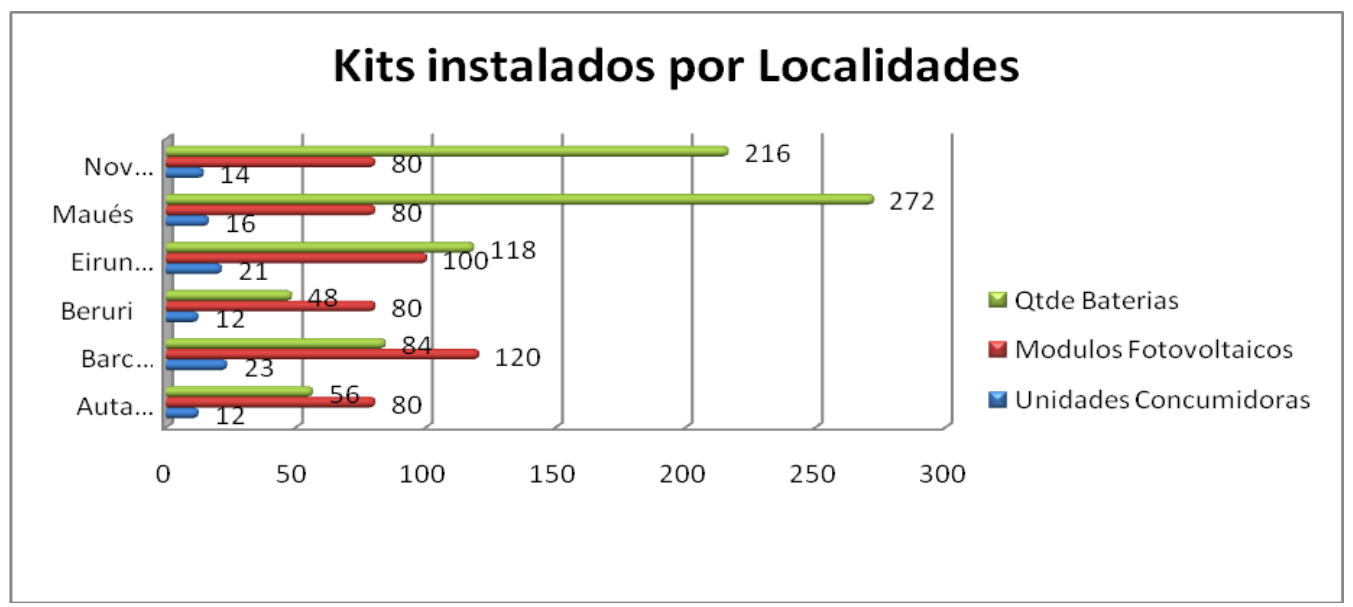

Figura 9. Sistemas Instalados.

Fonte: [8]. 
Rômulo Cabral, Marcos Cesar, Jandecy Cabral Leite / ITEGAM-JETIA Vol.01, No 01, pp. 19-28. Março, 2015.

Não foi levado em consideração a demanda por unidade consumidora, mas a capacidade de geração dos equipamentos instalados nas localidades, possibilitando um consumo médio que variou entre 9.84 $\mathrm{KW} / \mathrm{h}$ em Barcelos indo até 12,32 KW/h em Autazes.

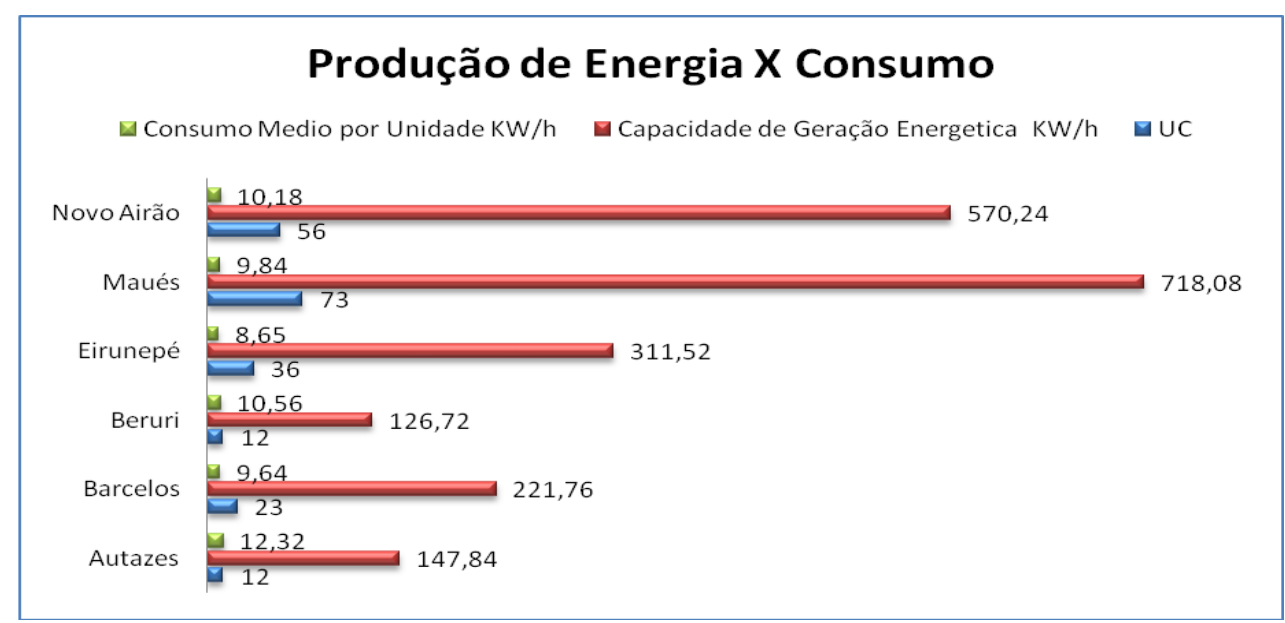

Figura 10. Unidades consumidoras e suas localidades. Fonte: [8].

Importante citar os valores energéticos disponíveis anualmente na região norte como um todo, onde valores mínimos são encontrados nos meses de Dezembro e Janeiro, e as maiores disponibilidades nos meses de Agosto e Setembro, Figura 10.

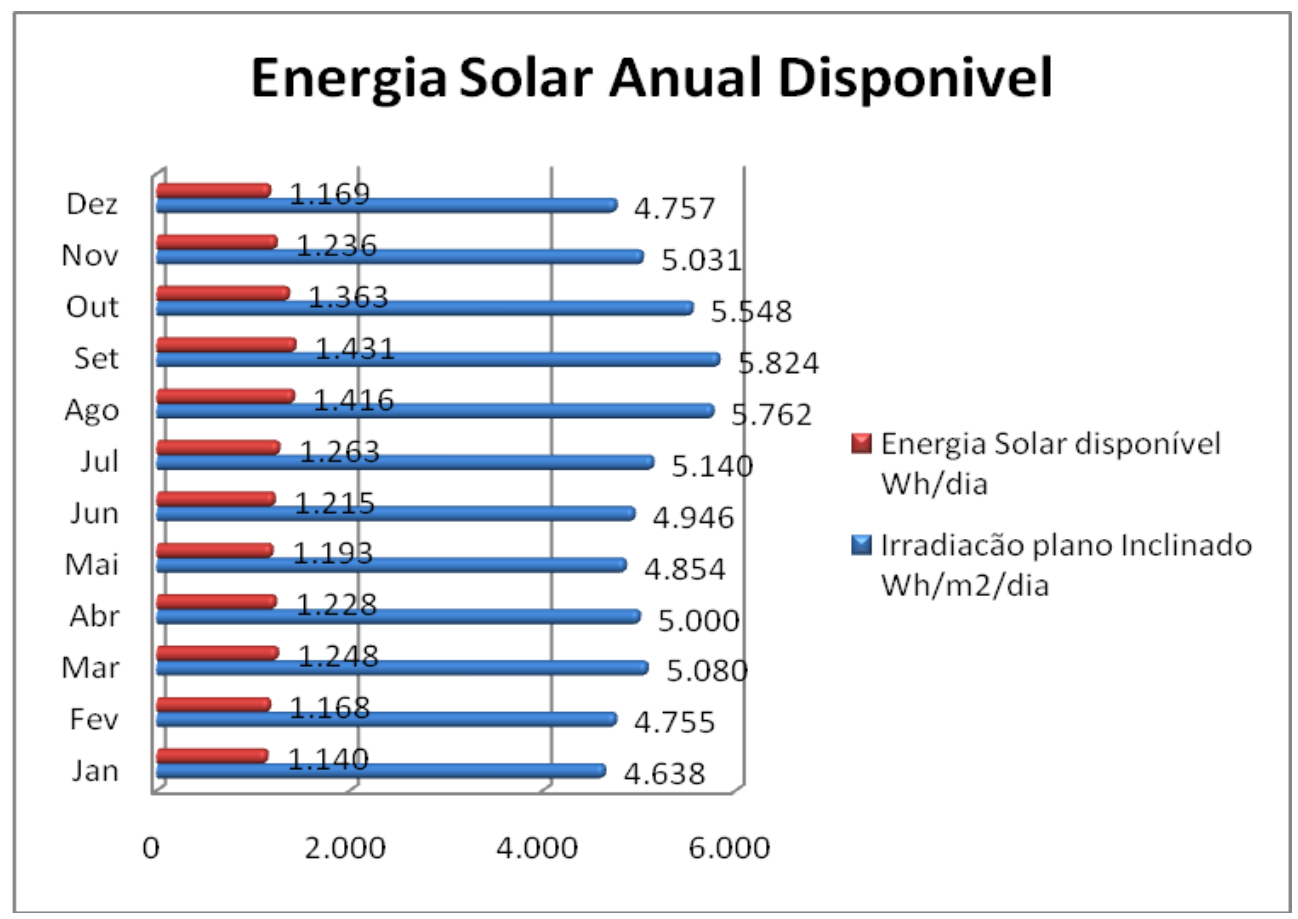

Figura 11. Sistemas Instalados.

Fonte: [14].

No total de 212 consumidores contemplados como mostram a Figura 9, o horizonte está aberto para o desenvolvimento e aproveitamento de recursos naturais antes inviáveis de serem armazenados, como por exemplo, em Autazes com seu pólo leiteiro e de derivados, em Barcelos com o comercio de peixes ornamentais ou ainda em Eirunepé com o destaque do terceiro setor, de serviços, que tem uma necessidade inegável de energia para prover áreas como comunicação e tecnologia para um 
melhor atendimento de clientes captados em praças como Rio Branco de Porto Velho.

$\mathrm{O}$ equipamento utilizado para tal feito tem origem no fabricante Kyocera um modelo FV KD 135 SX-UPU, Figura 12, que de acordo com a demanda nas comunidades tem sua quantidade instalada de modo a suprir as demandas do local e conjuntamente com outros equipamentos que são os inversores de potência que transformam a energia acumulada nas baterias para uma corrente utilizável nos aparelhos domésticos e iluminação em geral Já os controladores de carga completam o kit que se pode chamar de kit energia limpa.

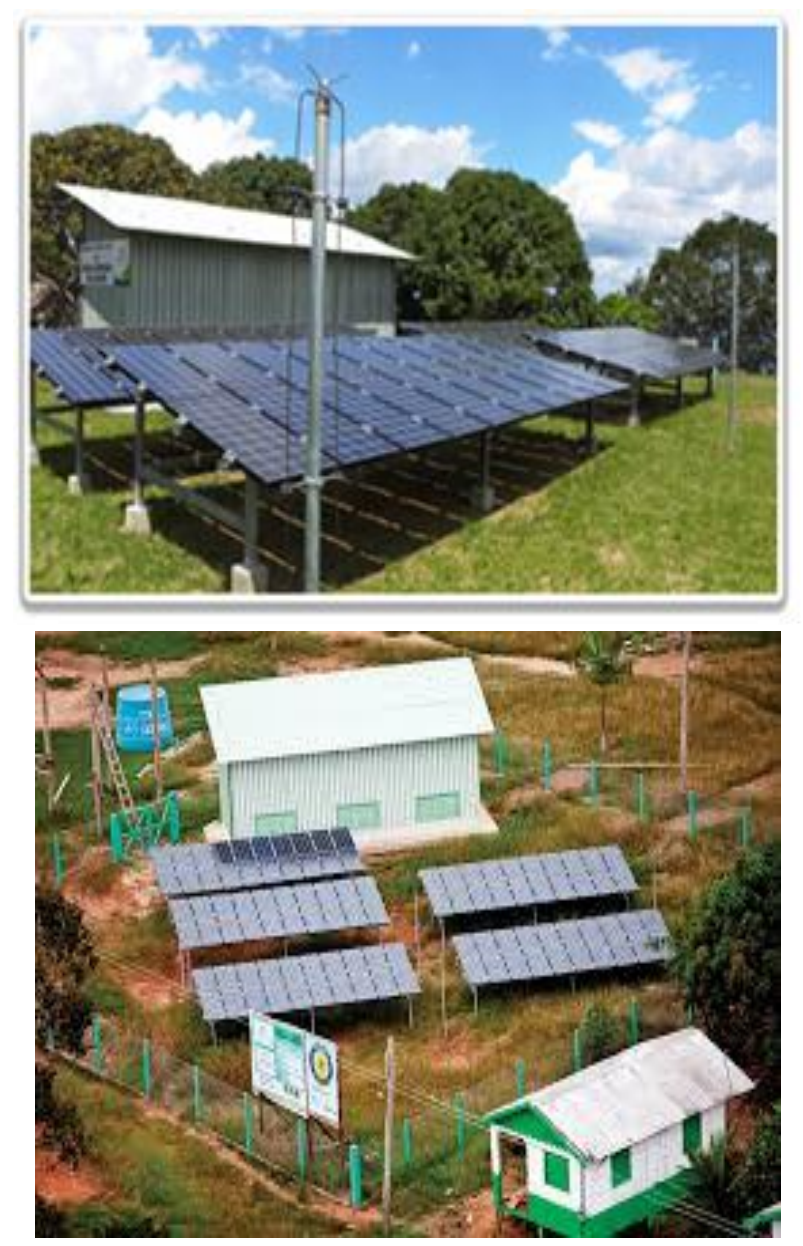

Figura 12. Mini usinas..

Fonte: [8].

Os sistemas fotovoltaicos são formados por: gerador fotovoltaico na forma de placas, um controlador de carga, baterias e inversor. A energia gerada nos módulos fotovoltaicos é armazenada nas baterias e aplicada ao inversor que a transforma para o modelo de corrente aceitável pelas unidades consumidoras para 127 ou 220VCA. O sistema FV isolado deve ser projetado para atender a demanda de energia com base nos meses de menor incidência de radiação solar, com isso a necessidade de um conjunto de baterias sendo responsável pelo aumento no custo de implantação, custo de manutenção e pela redução na produtividade da energia gerada.

Ainda considerando o ponto de vista energético, vale a pena ressaltar que, para a mesma quantidade de matéria prima inicial (uma tonelada de carbono, de petróleo, de urânio, ou de silício residual da indústria eletrônica), as quantidades de eletricidade produzidas são muito diferentes. Para se ter uma idéia, a eletricidade obtida do silício cristalino exposto ao sol é de 20 vezes superior à do urânio, 530 vezes à do petróleo e 820 vezes à do carbono (SERRASPLLES et al., 2004).

A Empresa de Pesquisa Energética - EPE em pesquisas de setembro de 2012 calculou o custo de produção de energia solar no Brasil era de R\$602,00 MWh, a partir do custo médio dos equipamentos necessários para suprir a demanda e ainda indica que é custo de produção mais barato que 10 mais caras produtoras de energia no Brasil.

\section{CONCLUSÕES}

No momento em que o mundo passa não mais por uma crise de petróleo, mas sim por uma mudança de pensamento onde a economia, no atual sistema, deve continuar em crescimento, mas com olhar da sustentabilidade. Sustentabilidade na visão de [15] defende a ideia que para haver uma revolução do pensamento, deve haver um planejamento para que haja uma proteção e monitoramento para a interação seja saudável entre os atores envolvidos aqui neste caso a natureza e homem.

$\mathrm{Na}$ aplicação de sistemas fotovoltaicos para a geração de energia e inegável o investimento superior na implantação, mas também incontestável na redução dos custos com combustíveis para o funcionamento tornando seus valores em manutenção irrisórios comparados aos modelos existentes. $\mathrm{O}$ fator ambiental não pode ser deixado de lado nessa discussão sobre produção de energia com o aproveitamento do sol não modifica o equilíbrio térmico da Terra. Não obstante é afirmação dessa pesquisa que as plantas solares não causarem impactos como poluição térmica.

Os objetivos dessa pesquisa foram plenamente alcançados levando em consideração o planejamento do projeto Luz para Todos do governo brasileiro, mas como todo e qualquer sistema exigindo intervenções através de manutenções regulares.

No Brasil com todo o conhecimento desenvolvidos nas academias e centros de P\&D, é ínfimo o que se utiliza dessas informações. Programas como o Luz para Todos que resolvendo problemáticas com inventividade e técnica para suprir as grandes 
Rômulo Cabral, Marcos Cesar, Jandecy Cabral Leite / ITEGAM-JETIA Vol.01, No 01, pp. 19-28. Março, 2015.

distancias amazônicas como demonstrada onde as soluções fotovoltaicas estão instaladas.

A capacidade de produção energética é infinita comparada com disponibilidade de radiação enviada pelo sol, assim produção de energia em regiões isoladas pode determinar o desenvolvimento ou não dessa região, bastando apenas aplicar todo o conhecimento já existente e em constante aprimoramento.

\section{AGRADECIMENTOS:}

Ao Centro Universitário do Norte (UNINORTE) e ao Instituto de Tecnologia e Educação Galileo da Amazônia (ITEGAM) pelo apoio à pesquisa.

\section{REFERÊNCIAS BIBLIOGRÁFICAS}

[1] GOLDEMBERG,José: http:// colunas. revistaepoca. globo.com/ planeta/ 2012/05/24/ jose-goldemberg-a-rio20-podenao-fazer-diferenca/. Acessado em 23/05/2014 as 23:35 hs.

[2] LUCENA, A.; SCHAEFFER, R. Mudança do Clima e Economia Verde. In: Caminhos para a sustentabilidade. Cadernos Adenauer XIII, Fundação Konrad Adenauer no Brasil, p. $31-51,2012$.

[3] BOYLE (ed.) G. Renewable Energy: Power for a Sustainable Futures. $3^{\circ}$ ed. UK: Oxford University, 2012.

[4] ATLAS BRASILEIRO DE ENERGIA ELÉTRICA ANEEL, São José dos Campos $3^{\mathrm{a}}$ Edição - 2012.

[5] CENBIO - Centro Nacional de Referência em Biomassa (Brasil). Relatório Projeto GASEIFAMAZ. São Paulo, 2001.

[6] AMAZONAS DISTRIBUIDORA DE ENERGIA S.A. Relatório de Administração 2010, Manaus - AM, 2010.

[7] VILlALVA, M. G.; GAZOLI, J. R. Energia Fotovoltaica: Conceitos e Aplicações, $1^{\circ}$ ed.; São Paulo: Érica, 2012.

[8] ELETROBRÁS AMAZONAS ENERGIA, Resumo do Projeto Mini usinas Fotovoltaicas com Mini rede de Distribuição de Energia Elétrica, 2012.

[9] ELETROBRAS: ATLAS BRASILEIRO DE ENERGIA SOLAR, São José dos Campos $1^{\mathrm{a}}$ Edição - 2006.

[10] MINISTÉRIO DA MINAS DE ENERGIA (MME). Plano Nacional de Energia 2020-2030. Outras Fontes - Vol. 9, 2007.

[11] GAGNON, Luc; BÉLANGER; Camille, UCHIYAMA; Yohji. Life-cycle assessment of electricity generation options: The status of research in year 2001. Energy Policy, 30, p.1267$1278 ; 2002$.
[12] WILLAMY M. FROTA, WHYLKER M. FROTA, JOSÉ A. S. SÁ, ARTHUR C. ALMEIDA, BRÍGIDA R. P. ROCHA, J. PISSOLATO FILHO. Avaliação Econômica da Inserção do Gás Natural da Amazônia na Matriz Elétrica da Cidade de Manaus, Estado do Amazonas. Simposio Brasileiro de Sistemas Elétricos. Foz do Iguaçu, Paraná, 2012.

[13] SERRASOLLES, J., DE CASTELLET, L., ANCOECHEA, M. e ROMEU, J. (2004). Tejados Fotovoltaicos: Energía Solar Conectada a la Red Eléctrica. PROGENSA (Promotora General de Estudios, S.A.).

[14] Global Solar Atlas, Solar and Wind Energy Resource Assessment (SWERA). 2012.

[15] SACHS, Ignacy. Caminhos para o desenvolvimento sustentável. Organização: Paula Yone Stroh. Rio de Janeiro: Garamond, 2008. 